DOI: https://doi.org/10.36910/6775-2524-0560-2021-43-27

УДК 621.914 .32

Юшков Андрій Генадійович, провідний науковий співробітник

https://orcid.org/0000-0002-4912-478X

Український науково-дослідний інститут спеціальної техніки та судових експертиз Служби безпеки України

\title{
ДЕЯКІ АСПЕКТИ ПРОЕКТУВАННЯ ДЕТАЛЕЙ ТА РОЗРОБКИ УПРАВЛЯЮЧОЇ ПРОГРАМИ В САD/САМ-СИСТЕМІ, ЩО ВПЛИВАЮТЬ НА СУМАРНУ ПОХИБКУ ВИГОТОВЛЕННЯ ВИРОБУ НА ФРЕЗЕРНОМУ ВЕРСТАТІ 3 ЧПУ
}

\begin{abstract}
Юшков А. Г. Деякі аспекти проектування деталей та розробки управляючої програми в CAD/CAM-системі, що впливають на сумарну похибку виготовлення виробу на фрезерному верстаті з ЧПУ. Стаття присвячена питанням аналізу взаємозв'язку проектування деталей в CAD/CAM-системі та їх виготовлення на фрезерних верстатах 3 ЧПУ. Розглянуто причини виникнення похибок виготовлення деталей на фрезерних верстатах з ЧПУ та шляхи їх усунення не тільки в процесі самого фрезерування деталі на виробничому обладнанні, а і на етапах проектування конструкції, розробки управляючих програм (УП) для оброблювального центру та розрахунку режимів різання та їх взаємозв'язок. Запропонована структура сумарної похибки виготовлення деталей, що впливає на загальну якість виробу, на верстаті з ЧПУ. Наголошено, що сумарна похибка складається з похибки, що формується апаратними можливостями верстата, похибки, що може бути закладена при розробці 3D-моделі деталі в номінальних розмірах, похибки, що може виникнути при некоректній розробці УП для верстата з ЧПУ та похибки пов'язаної з особливостями управляючої системи конкретного верстата з ЧП. Підкреслено, що при аналізі взаємодії CAD/CAM-системи та верстата з ЧПУ за основу були взяті CAD-система SolidWorks компанії Dassault Systemes та CAM - система SolidCAM з інтегрованим модулем інтелектуальної обробки iMachining компанії SolidCAM Ltd., тому що вона являє собою комплексну САМ-систему, яка призначена для програмування верстатів з ЧПУ в середовищі SolidWorks. Запропоновано структурну схему CAD/CAM система - верстат з ЧПУ, на базі якої детально представлено взаємозв'язок оператора з верстатом та управляючою системою. Особлива увага приділена впливу параметрів 3D-моделі деталі (CAD-система) та оптимізованої програми обробки (САМ-система з інтегрованим модулем iMachining) на сумарну похибку виготовлення деталей на фрезерному верстаті з ЧПУ та вкінцевому випадку на якість виробу в цілому. Обгрунтовано, що запропонований підхід та рекомендації до процесу розробки конструкції, написання управляючої програми до верстата 3 ЧПУ та методів фрезерування деталей дозволить максимально зменшити сумарну похибку виготовлення виробу.
\end{abstract}

Ключові слова: верстат з ЧПУ, САD/САМ-система, режими різання, модуль iMachining, управляюча програма.

Юшков А. Г. Некоторые аспекты проектирования деталей и разработки управляющей программы в CAD / САМ-системе, влияющие на суммарную погрешность производства изделия на фрезерном станке с ЧПУ. Статья посвящена вопросам анализа взаимосвязи проектирования деталей в CAD / CAM-системе и их изготовления на фрезерных станках с ЧПУ. Рассмотрены причины возникновения погрешностей изготовления деталей на фрезерных станках с ЧПУ и пути их устранения не только в процессе самого фрезерования детали на производственном оборудовании, а и на этапах проектирования конструкции, разработки управляющих программ (УП) для обрабатывающего центра и расчета режимов резания и их взаимосвязь. Предложенная структура суммарной погрешности изготовления деталей, которая влияет на общее качество изделия, на станке с ЧПУ. Отмечено, что суммарная погрешность состоит из погрешности, которая формируется аппаратными возможностями станка, погрешности, которая может быть заложена при разработке 3D-модели детали в номинальных размерах, погрешности, которая может возникнуть при некорректной разработке УП для станка с ЧПУ и погрешности связанной с особенностями управляющей системы конкретного станка с ЧП. Подчеркнуто, что при анализе взаимодействия CAD / CAM-системы и станка с ЧПУ за основу были взяты CAD-система SolidWorks компании Dassault Systemes и CAM - система SolidCAM с интегрированным модулем интеллектуальной обработки iMachining компании SolidCAM Ltd., так как она представляет собой комплексную САМ- систему, которая предназначена для программирования станков с ЧПУ в среде SolidWorks. Предложена структурная схема CAD / САМ система - станок с ЧПУ, на базе которой подробно представлена взаимосвязь оператора со станком и управляющей системой. Особое внимание уделено влиянию параметров 3D-модели детали (CAD-система) и оптимизированной программы обработки (CAM-система с интегрированным модулем iMachining) на суммарную погрешность изготовления деталей на фрезерном станке с ЧПУ и в конечном случае на качество изделия в целом. Обосновано, что предложенный подход и рекомендации к процессу разработки конструкции, написание управляющей программы к станку с ЧПУ и методов фрезерования деталей позволит минимизировать суммарную погрешность изготовления изделия. программа.

Ключевые слова: станок с ЧПУ, САD/САМ-система, режимы резания, модуль iMachining, управляющая

Yushkov Andriy. Some aspects of designing parts and developing a control program in a CAD / CAM system affecting the total error of product production on a CNC milling machine. The article is devoted to the analysis of the relationship between the design of parts in a CAD / CAM system and their manufacture on CNC milling machines. The reasons for the occurrence of errors in the manufacture of parts on CNC milling machines and ways of eliminating them not only in the process of milling the part on production equipment, but also at the stages of design design, development of control programs (PC) for the machining center and calculation of cutting modes and their relationship are considered. The proposed structure of the total manufacturing error of parts, which affects the overall quality of the product, on a CNC machine. It is noted that the total error consists of the error that is formed by the hardware capabilities of the machine, the error that can be incorporated in the development of a 3D model of the part in nominal dimensions, the error that may arise with the incorrect development of the control unit for a CNC machine and the error associated with the features of the control systems of a specific machine tool with PE. It was emphasized that when analyzing the interaction of a CAD / CAM system and a CNC machine tool, the SolidWorks CAD system from Dassault Systemes and CAM, a SolidCAM system with an integrated iMachining intelligent processing module from SolidCAM Ltd., were taken as a basis, since it is a complex CAM-

(C) Юшков А. Г. 
a system that is designed for programming CNC machines in the SolidWorks environment. A structural diagram of a CAD / CAM system is proposed - a CNC machine, on the basis of which the interaction of the operator with the machine and the control system is presented in detail. Particular attention is paid to the influence of the parameters of the 3D model of the part (CAD system) and the optimized processing program (CAM system with the integrated iMachining module) on the total error in the manufacture of parts on a CNC milling machine and, ultimately, on the quality of the product as a whole. It is substantiated that the proposed approach and recommendations for the design development process, writing a control program for a CNC machine and methods for milling parts will minimize the total error in manufacturing a product.

Keywords. CNC milling machine, CAD/CAM-system, cutting modes, milling modes, iMachining module, controlling program.

Сучасному виробництву в галузі приладобудування та машинобудування притаманне постійне збільшення темпів виробництва одночасно з зростаючими вимогами точності виготовлення деталей. Тенденції розвитку сучасного виробництва потребують заміни застарілого універсального обладнання на новітні верстати з числовим програмним управлінням (ЧПУ). Це обладнання дозволяє вирішувати великий обсяг задач та прискорювати виробничі процеси, даючи цим самим нові виробничі можливості, виготовляти тисячі одиниць ідентичної продукції 3 додержуванням стовідсоткової точності розмірів. Для того щоб виконати чистовий розмір в полі допуску, на верстаті з ручним управлінням треба кілька разів зупиняти верстат і проводити контрольні заміри.

Верстат з ЧПУ дозволяє виконати повний цикл обробки не зупиняючи процес, при цьому відхилення від заданих розмірів чи шорсткості поверхні визначаються технічними характеристиками верстата.

Проте, складне улаштування верстата з ЧПУ передбачає велику кількість похибок пересувань вузлів, які відслідковуються схемою внутрішнього моніторингу верстата. Сумарна похибка має комплексний вид і являє собою функцію численності змінних. Зняття параметрів 3 датчиків при виникненні тої чи іншої похибки та порівняння цих показників з референтними можуть бути вихідними даними для розробки заходів зі зменшенню сумарної похибки. Більшість робіт в сучасній технічній літературі присвячені питанням дослідження формування похибок, що випливають 3 принципів внутрішньої побудови верстатів. Більшість досліджень присвячені питанням прогнозування та вимірювання зношення інструменту за допомогою різноманітних методів $[1,2]$. Автори пропонують за показниками потужності шпинделя прогнозувати зношення інструменту. В деяких роботах досліджується вібраційний вплив на процес різання [3] . Вимірювання вібрації також дозволяє провести математичне моделювання для подальшого передбачення шорсткості поверхні, що обробляється, та таким чином вплинути на зменшення сумарної похибки [4] .

Bci ці дослідження аналізують отримані похибки в процесі виготовлення безпосередньо на верстаті тільки апаратними методами. У той же час, незважаючи на значну кількість наукових публікацій, що присвячені дослідженню цієї проблеми, в технічній літературі дуже мало приділено уваги (в деяких питаннях і зовсім не досліджено) іншим аспектам процесу розробки та виготовлення деталей на верстатах з ЧПУ, в частині впливу інших факторів на сумарну похибку виготовлення.

Отже автором цієї статі пропонується розглянути причини виникнення похибок виготовлення деталей на фрезерних верстатах з ЧПУ та шляхи їх усунення не тільки в процесі самого фрезерування деталі на виробничому обладнанні, а і на етапах проектування конструкції, розробки управляючих програм (УП) для оброблювального центру та розрахунку режимів різання та їх взаємозв'язок. Зважаючи на це, запропонована структура сумарної похибки виготовлення деталей, що впливає на загальну якість виробу, на верстаті з ЧПУ може бути представлена в формі, як зображено на рисунку 1. 


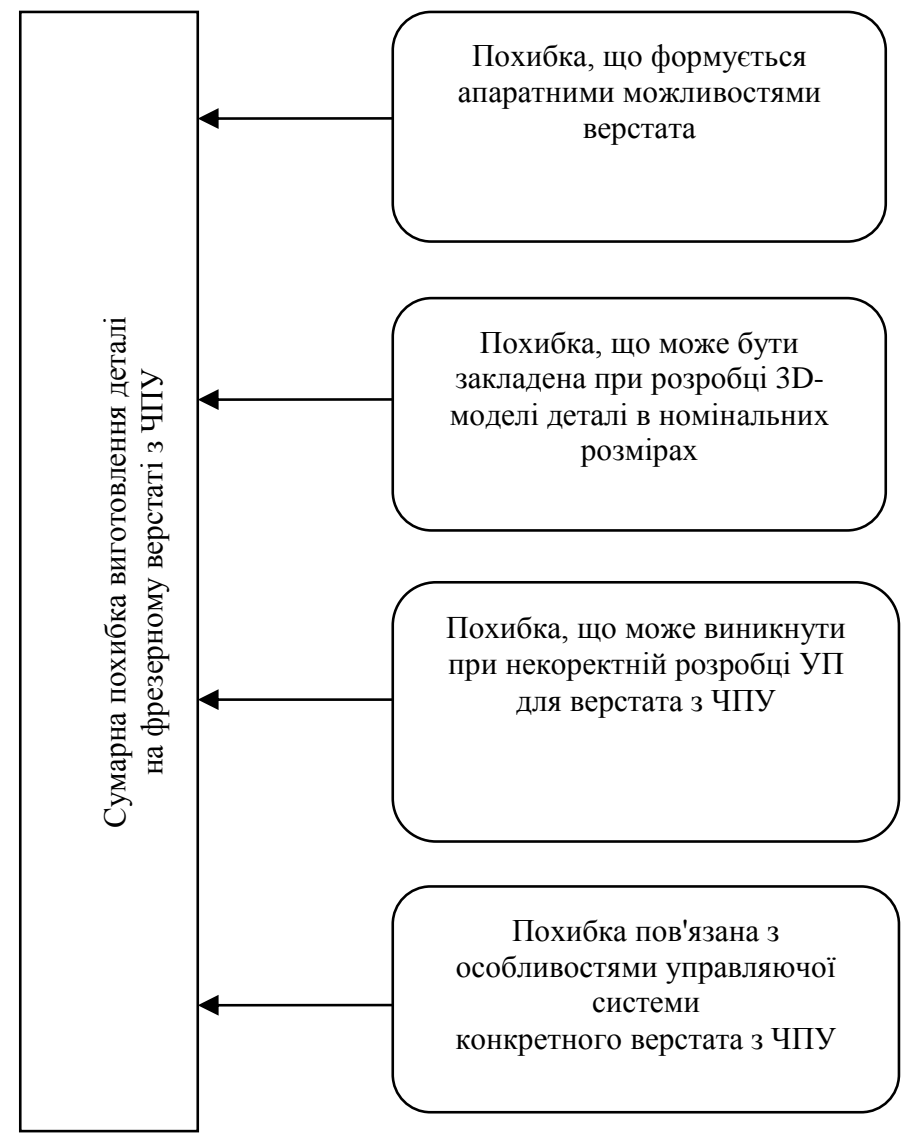

Рис. 1. Структура сумарної похибки виготовлення деталі на фрезерному верстаті з ЧПУ

На першому етапі розробки та виготовлення для проектування деталей використовується CAD система. CAD-система (computer-aided design) - це програмне забезпечення, яке автоматизує роботу інженера-конструктора та дозволяє вирішувати задачі проектування виробів та оформлення технічної документації за допомогою комп'ютера.

На другому етапі потрібна розробка УП для верстата з ЧПУ. Для сучасних верстатів з ЧПУ існує три метода програмування обробки та створення УП: ручне програмування; програмування на стійці управляючої системи верстату з ЧПУ; програмування за допомогою САМ-системи.

Ручне програмування це тривалий, монотонний та одноманітний процес.

За своєю продуктивністю та якістю ручне програмування програє методу за допомогою системи автоматизованого проектування (САМ-система).

При програмуванні на стійці управляючої системи верстата з ЧПУ програма створюється безпосередньо на екрані стійці, використовуючи клавіатуру верстата.

Програмування за допомогою системи автоматизованого проектування (САМ-система) найпрогресивніший, зручний та самий швидкісний метод розробки УП серед існуючих на даний момент. САМ-система (computer-aided manufacturing) - це програмне забезпечення за допомогою якого автоматизують розрахунки траєкторії переміщення інструменту для обробки на верстатах з ЧПУ та забезпечують створення УП за допомогою комп'ютера.

При аналізі взаємодії CAD/CAM-системи та верстата з ЧПУ за основу були взяті CAD-система SolidWorks компанії Dassault Systemes та CAM - система SolidCAM 3 інтегрованим модулем інтелектуальної обробки iMachining компанії SolidCAM Ltd., тому що вона являє собою комплексну САМ-систему, яка призначена для програмування верстатів з ЧПУ в середовищі SolidWorks. CAMсистема SolidCAM з інтегрованим модулем iMachining повністю вбудовується до CAD SolidWorks, при цьому зберігається повна асоціативність між траєкторією руху інструмента та 3D- моделлю. Bсі переходи, необхідні для обробки деталі, можуть бути визначені та перевірені безпосередньо у вікні CAD-системи, без виходу із параметричного середовища побудови спроектованої деталі, що сомо по собі зменшує похибку в кінцевому результаті. 
При використанні стратегії iMachining, як і при високошвидкісних обробках, відбувається видалення невеликого припуску, однак траєкторія цим модулем створюється таким чином, що врізання інструмента йде на повну глибину з постійним зняттям припуску сталої товщини. За рахунок цього, а також ефективно використовуючи різальну довжину інструмента та потужності верстата, підвищується продуктивність обробки [5].

Модуль iMachining може аналізувати конструктивні особливості деталі для зменшення холостих проходів, що сприяє зменшенню часу обробки [6].

При цьому видалення стружки зі сталою товщиною забезпечує зменшення перепадів навантаження, що виникають в процесі різання, та призводить до збільшення терміну служби верстата [7] . Для розрахунку траєкторії в модулі iMachining необхідно вказати параметри верстата: максимальні оберти шпінделя, максимальну подачу, потужність та ін., також необхідно вказати тип матеріалу, що обробляється, та параметри інструменту. На базі цього визначаються оптимальні режими різання (в межах технічних характеристик конкретного верстата). Це дозволяє скоротити час на розробку програми та технологічну підготовку виробництва [8].

Запропонована автором статті загальна структурна схема взаємодії CAD/CAM-системи та верстата 3 ЧПУ представлена на рисунку 2.

Зазвичай проектування за технічним завданням відбувається виходячи з вимог оптимальної конструкції, умов зручності складання виробу, його ремонту та експлуатаційних характеристик. Конструктор, як правило, зважає на можливий спосіб виробництва деталей, виходячи з того, що вони можуть бути виготовлені на різноманітному універсальному обладнанні. Тому використовує номінальні розміри для розробки 3D-моделі деталі (за винятком сполучених поверхонь, до яких пред'являється особлива точність

виготовлення), не зважаючи на закладені допуски, зазначені в конструкторській документації (КД) на даний виріб.

Номінальний розмір (D) це розмір, відносно якого визначаються граничні розміри та який слугує також началом відліку відхилень.

Граничні розміри (Dмax, Dmin) це два допускні розміри, між якими повинен знаходитись або може дорівнювати дійсний розмір.

Відхилення (ES - верхнє відхилення, EI - нижнє відхилення) це алгебраїчна різниця між розміром (дійсним чи граничним) та відповідним номінальним розміром.

Дійсний розмір це розмір, що встановлений вимірюванням 3 допустимою похибкою.

Зв'язок між наведеними параметрами виражається наступними формулами:

$$
\begin{aligned}
& \text { Dмax }=\mathrm{D}+\mathrm{ES} \\
& \text { Dmin }=\mathrm{D}+\mathrm{EI}
\end{aligned}
$$

Отже різниця між максимальним та мінімальним граничними розмірами або між верхнім та нижнім відхиленнями і є допуск (TD), в рамках якого може бути виконаний дійсний розмір:

$$
\mathrm{TD}=\mathrm{Dmax}-\mathrm{Dmin}=\mathrm{ES}-\mathrm{EI}
$$

При виготовлені деталей на універсальному обладнанні отримання дійсного розміру в межах заданого допуску (TD) супроводжується періодичним зупиненням обладнання, а іноді і зняттям заготівки з верстату, для контрольного вимірювання розмірів. Якщо ця сама деталь виробляється на верстаті з ЧПУ, зупиняти та знову перезапускати програму не раціонально, а в деяких випадках $\mathrm{i}$ неможливо зовсім. Тому важливо, щоб граничні розміри (Dмax, Dmin) деталі були враховані конструктором при розробці в CAD-системі 3D-моделі, по якій в подальшому технолог-програміст буде писати програму для обробки на верстаті з ЧПУ. При цьому бажано, щоб лінійні та кутові розміри 3D-моделі були посередині допуску (TD), зазначеному в конструкторській документації (КД), а зовнішня та внутрішня різі були відображені гладкими отворами в розмірах діаметрів під нарізання відповідних різей. Такий підхід дасть можливість на другому етапі (рис.2) при розробці УП для верстата з ЧПУ позбавити технолога-програміста від рутинних механічних розрахунків, необхідних для цього, та мінімізувати вплив недостатньої жорсткості системи верстат - приладдя - інструмент деталь (ВПІД), тому як похибки від пружних деформацій системи ВПІД, не відповідності конструкції та точності приладдя (може складати десяті долі міліметра), типу інструмента технічним характеристикам конкретного верстата з ЧПУ (зазвичай точність верстатів такого типу складає не більше 0,01 мм) складає в окремих випадках до $80 \%$ загальної похибки механічної обробки. 


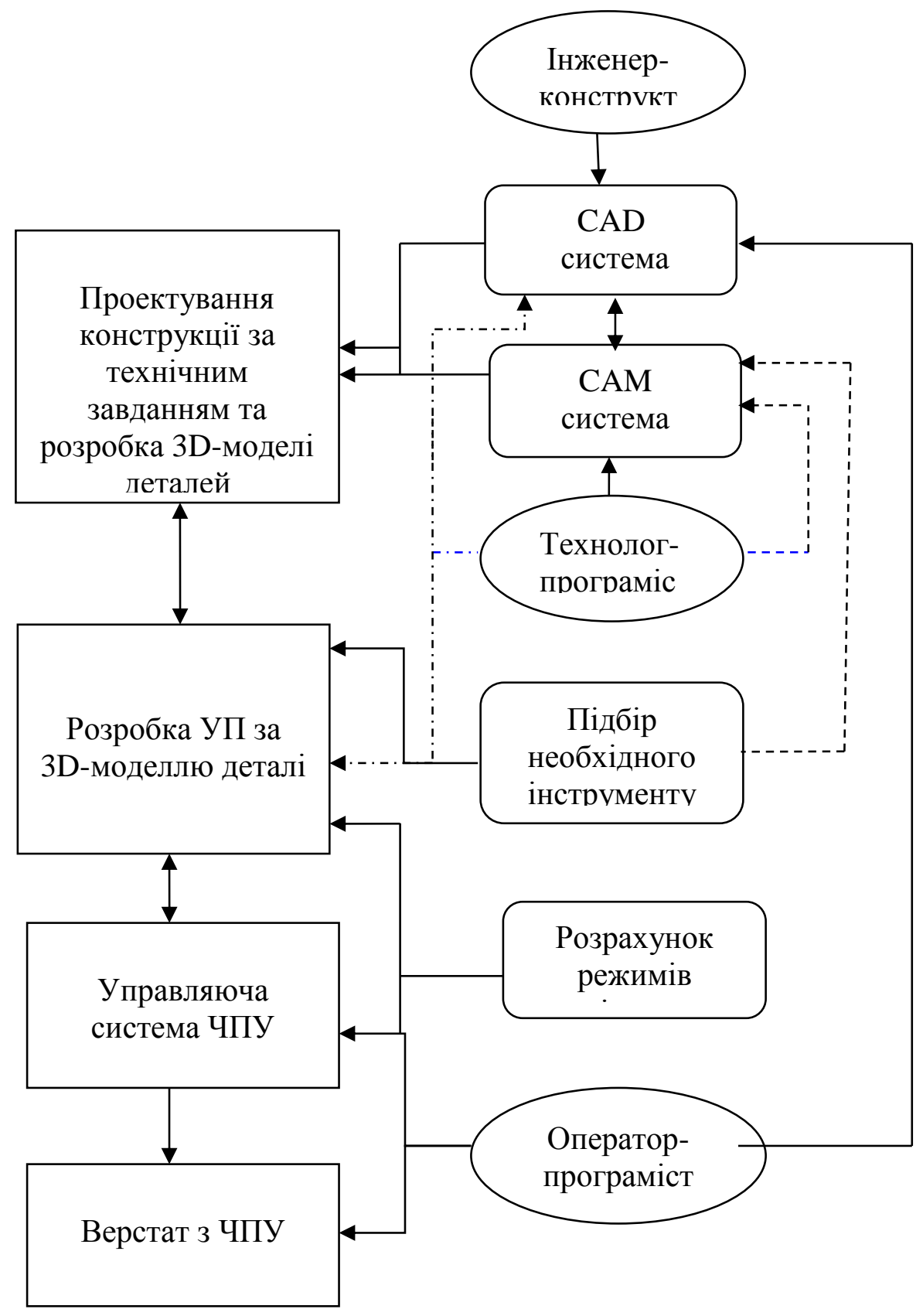

Рис. 2. САD/САМ система - верстат з ЧПУ

Наступний крок полягає в розробці УП для верстата з ЧПУ. 3 трьох методів розробки УП найоптимальнішим $\epsilon$ метод програмування за допомогою САМ-системи, яка в декілька разів прискорює роботу технолога-програміста в порівнянні з ручним написанням програми, а використання інтегрованого модуля iMachining додатково полегшує цю роботу, при цьому, як вже було зазначено, важливо вказати параметри верстата, інструмента та матеріалу, що обробляється. Технолог-програміст вказує послідовність обробки деталі, а програма автоматично розраховує режими різання. В підсумку точність виготовлення деталі буде залежити тільки від закладених в програму параметрів, що не завжди задовольняє вимогам розробленої конструкції.

Щоб досягти необхідної точності та якості деталей, що виготовляються на верстатах з ЧПУ, необхідно втручання технолога-програміста, тому що в програму закладаються лише загальні параметри різання, такі як частота обертів шпинделя $(\mathrm{N}$, об/хв), подача стола верстата $(\mathrm{F}, \mathrm{Mm} / \mathrm{xв})$ та діаметр фрези (D, мм). Однак на сумарну похибку виготовлення деталей на верстаті з ЧПУ найбільше впливає не просто частота обертів шпинделя (N) та діаметр фрези (D), а швидкість різання, яка визначається за формулою:

$$
\mathrm{V}=\pi \times \mathrm{D} \times \mathrm{N} / 1000(\text { об/хв })
$$


Тобто на похибку при обробці впливає правильне співвідношення частоти обертів шпинделя та діаметру інструмента.

Також необхідно мати на увазі кількість зубів фрези (Z), що використовується при конкретній обробці, тому що дуже велике значення має такий параметр, як подача на зуб, який залежить не тільки від точної кількості зубів конкретної фрези, а і від загальної подачі стола верстата (F) та розраховується за формулою:

$\mathrm{fz}=\mathrm{F} / \mathrm{N} \times \mathrm{Z}(\mathrm{Mm} / 3 \mathrm{y} \sigma)$

Значення подачі на зуб повинне знаходитись в розрахунковому співвідношенні 3 таким параметром як подача на оберт, що визначається за формулою:

$\mathrm{fn}=\mathrm{F} / \mathrm{N}(\mathrm{Mм} / \mathrm{o \sigma})$

Таким чином, оптимальне поєднання таких параметрів різання, як діаметр фрези (D), швидкість різання (V), подача на зуб (fz), подача на оберт (fn) та, якщо програма розроблена по 3Dмоделі, виконаної в номінальних розмірах, зазначених в КД, має в кінцевому результаті відобразитися на точності виготовлення та шорсткості поверхонь, що обробляються.

Для того щоб досягти найвищої точності та якості деталі, що виробляється на верстаті з ЧПУ, технолог-програміст не повинен покладатися на параметри обробки, запропоновані автоматично модулем iMachining, а провести інженерні розрахунки за наданими формулами і відкоригувати розроблену програму в частині значних відхилень відповідних параметрів.

До цього треба додати необхідність точного визначення матеріалу інструмента. Фрези виготовляються 3 матеріалів (інструментальні сталі, швидкорізальні сталі, тверді сплави) що дуже сильно відрізняються між собою за механічною стійкістю, швидкістю зношення, стійкістю до високих температур тощо. Також для різного матеріалу, що обробляється на верстаті з ЧПУ, фрези використовуються різні за конструкцією, розмірами і таке інше. Тому не менш важливо технологупрограмісту зважати на цей аспект і своєчасно корегувати програму під конкретний інструмент.

Після розробки та верифікації УП технологом-програмістом наступним кроком $є$ встановлення програми на управляючу систему верстата з ЧПУ, після чого можна приступати до роботи. Зазвичай так і робиться і оператор верстата тільки контролює процес виготовлення, не маючи можливості вплинути на нього ( часто оператор не має достатньої кваліфікації для цього).

Аналіз даного питання показує, що це не зовсім вірно, тому що похибка виготовлення, пов'язана 3 особливістю конкретного верстата з ЧПУ, дасться взнаки в кінцевому результаті. Тому важливо щоб оператор володів навичками ручного програмування на стійці управляючої системи верстату з ЧПУ для оперативного корегування процесу виготовлення деталі.

В підсумку можна зробити висновок, що всупереч традиційних підходів до аналізу похибки виготовлення деталей на фрезерних верстатах з ЧПУ, точність та якість кінцевої продукції залежить не тільки від апаратних параметрів роботи обладнання (точність позиціонування, повторюваність, зношеність обладнання тощо), а і від похибок на етапах розробки 3-D моделі деталі, що виготовляється, написання програми та особливостей управляючої системи конкретного верстата 3 ЧПУ (рис.1). Також, як можна бачити на рис.2, в процесі виготовлення деталі, починаючи від іiі проектування і розробки технології, приймають участь декілька спеціалістів (інженер-конструктор, технолог-програміст, оператор верстата з ЧПУ). І коли при серійному виготовленні продукції цей поділ абсолютно виправданий (за умови що до цього розроблена програма для верстата з ЧПУ була відпрацьована на цьому верстаті 3 конкретним приладдям та інструментом), то вразі опитного виробництва (виготовлення дослідних зразків чи дослідних партій) або одиничного виробництва (чи разове виготовлення виробу) це не дуже раціонально з точки зору максимальної мінімізації сумарної похибки проектування та виготовлення деталей на верстатах з ЧПУ. Тому в такому випадку для досягнення більш якісного результату (при менших витратах часу) дуже бажано, щоб розробку 3-D моделі деталі, УП для верстата 3 ЧПУ і управління системою верстата (при необхідності поточного корегування програми) здійснював один спеціаліст достатньої кваліфікації.

Таким чином, запропонований підхід та рекомендації до процесу розробки конструкції, написання управляючої програми до верстата з ЧПУ та методів фрезерування деталей дозволить максимально зменшити сумарну похибку виготовлення виробу.

References.

1. Jain A.K., Lad B.K. A novel integrated tool condition monitoring system. Journal of Intelligent Manufacturing. June 2017. P. 1-14.

2. Nitin Ambhore, Dinesh Kambleb, Satish Chinchanikar, Vishal Wayal. Tool condition monitoring system: A review. Materials Today: Proceedings 2.2015. P. 3419-3428.

3. Alonso F.J., Salgado D.R. Analysis of the structure of vibration signals for tool wear detection. Mechanical Systems and Signal Processing. Issue 3. 2008. P. 735-748.

(C) Юшков А. Г. 
4. Rao K.V., Murthy B.S.N., Rao N.M. Cutting tool condition monitoring by analyzing surface roughness, work piece vibration and volume of metal removed for AISI 1040 steel in boring. Measurement, 2013. P. 4075-4084.

\section{Список бібліографічного опису.}

1. Ловигін А.A. SolidCAM: наша сила в iMachining. Планета CAM. URL : http:// planetacam.ru/articles/ exclusive/solidcam_nasha_sila_v_machining/

2. Somekh E. Design with SolidWorks. Manufacture with SolidCAM. Bielefeld: VDW-Nachwuchssiftung GmbH, 2015. 230 p. ISBN 978-3-942817-28-8.

3. Старков В.К. Фізика та оптимізація різання матеріалів. М.: Машінобудування, 2009. 640 с.

4. Самарцев A.A. Imachining 3D. Логічний розвиток технологіï. CADmaster, 2013. №2(69). С. 60-63 